\title{
Brief Introduce of Planetary K-index: An Indicator of Geomagnetic Storms
}

\author{
Jyh-Woei Lin
}

\section{ABSTRACT}

The planetary K-index (Kp index) was a geomagnetic index in the $\mathrm{H}$ component field. This index was calculated from data collected by a network of 13 ground-based magnetometer stations at mid-latitude locations from the International Real-time Magnetic Observatory Network (INTERMAGNET). The magnitudes of $\mathrm{Kp}$ index could indicate geomagnetic activity using the integer $\mathrm{K}$-scale from 0 to 9 without dimension because the $\mathrm{K}$-scale was estimated using the quasi-logarithms algorithm. The $\mathrm{Kp}$ index indicated geomagnetic storms under the condition of $\mathrm{K}$-scale $>4$. The three-hourly Kp index has been commonly used. The three-hourly Kp index was relatively stable for low-variability geomagnetic activity. The hourly $\mathrm{Kp}$ index represented the level of auroral absorption with a more accurate characterization. For future research, the $\mathrm{Kp}$ index with a high sampling rate (e.g., $<1$ hour) could be considered, so that a very accurate characterization was characterized the more detailed geomagnetic activity of global region.

Published Online: October 16, 2021

ISSN: $2684-446 \mathrm{X}$

DOI : $10.24018 /$ ejgeo.2021.2.5.190

Jyh-Woei Lin*

Binjiang College, Nanjing University of Information Science \& Technology, Wuxi, 214105, Jiangsu Province, China.

Department of Electrical Engineering, Southern Taiwan University of Science and Technology, Tainan, Taiwan

(e-mail: pgjw11966@gmail.com)

*Corresponding Author

Keywords: International Real-time Magnetic Observatory Network (INTERMAGNET), Geomagnetic Storms, K-scale, Low-Variability Geomagnetic Activity, Quasi-logarithms Algorithm, Planetary K-index (Kp index).

\section{INTRODUCTION}

The planetary K-index (Kp index), which was a geomagnetic index in the H-component field, was calculated from data collected by a network of ground-based magnetometer stations at mid-latitude locations from the International Real-time Magnetic Observatory Network (INTERMAGNET) [1] indicated that the magnitudes of geomagnetic activity could be characterized using the integer $\mathrm{K}$-scale from 0 to 9 without dimension because the K-scale was quasi-logarithmic using the quasi-logarithms algorithm as shown in Fig. 1 and Table I [2]-[9].

\section{AN INDICATOR OF GEOMAGNETIC STORMS}

The Kp was an excellent indicator, which was used to decide whether geomagnetic alerts should be sent (World Data Center for Geomagnetism, Kyoto). The Kp index could describe the detailed features of a geomagnetic storm under the condition of K-scale $>4$ shown in Table I. The threehourly Kp index (sampling rate: per three hours) has been commonly used. For low-variability geomagnetic activity, the three-hourly Kp index was relatively stable, which could reflect the apparent characterization of the geomagnetic activity. Hence, determining the temporal resolution of the $\mathrm{Kp}$ index depended on the local dynamic characterization of the geomagnetic activity. The hourly $\mathrm{Kp}$ index provided a more accurate characterization, which could represent the level of auroral absorption [10], [11]. For future research, the Kp index with a high sampling rate (e.g., $<1$ hour) could be a good issue, so that a very accurate characterization was characterized the more detailed geomagnetic activity of global region.

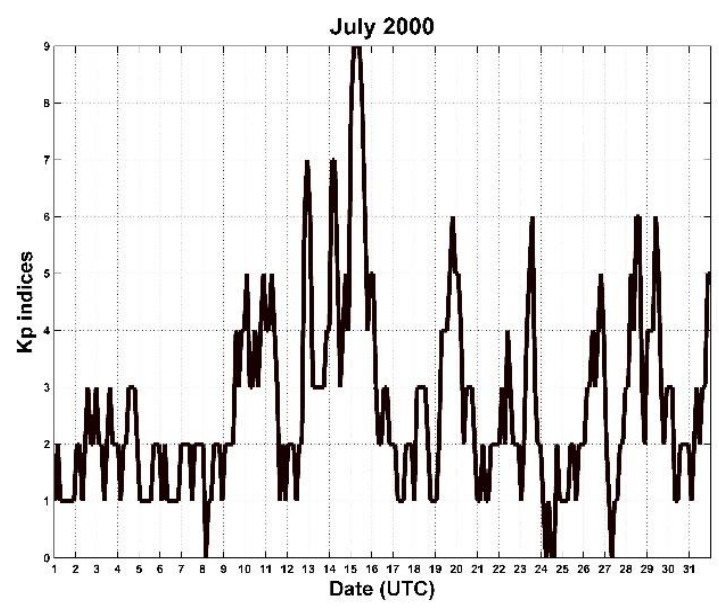

Fig. 1. The Kp indices for July 2000 (UTC).

(Source: World Data Center for Geomagnetism, Kyoto).

The horizontal time scale from 1 to 2 indicates the variation in the Kp indices on 01 July 2000 as an example. 
TABLE I: THE KP INDEX RELATED TO EARTH'S MAGNETIC FIELD

\begin{tabular}{|c|c|}
\hline $\begin{array}{c}\text { The value of } \\
\text { Kp index }\end{array}$ & Description \\
\hline 0 & $\begin{array}{l}\text { Quiet - Aurora oval mostly to the north of Iceland. Faint } \\
\text { aurorae visible in photographs, low in the northern sky. }\end{array}$ \\
\hline 1 & $\begin{array}{l}\text { Quiet - Aurora oval over Iceland. Faint and quiet aurorae } \\
\text { visible to the unaided eye. low in the northern sky. }\end{array}$ \\
\hline 2 & $\begin{array}{l}\text { Quiet - Auroras readily visible; become brighter and more } \\
\text { dynamic. }\end{array}$ \\
\hline 3 & $\begin{array}{l}\text { Unsettled - Bright auroras visible at zenith. Pale green color } \\
\text { more obvious. }\end{array}$ \\
\hline 4 & $\begin{array}{l}\text { Active - Bright, constant, dynamic northern lights visible. } \\
\text { More colors start to appear. }\end{array}$ \\
\hline 5 & $\begin{array}{l}\text { Minor storm - Bright, constant, colorful aurora display, red } \\
\text { and purple colors appear. Aurora coronae likely. } \\
\text { Moderate storm - Bright, dynamic, colorful aurora display. }\end{array}$ \\
\hline 6 & $\begin{array}{l}\text { Aurora coronae likely. Memorable to those who witness } \\
\text { them. }\end{array}$ \\
\hline 7 & $\begin{array}{l}\text { Strong storm - Bright, dynamic, colorful aurorae. Visible in } \\
\text { the southern sky. Aurora coronae very likely. }\end{array}$ \\
\hline 8 & $\begin{array}{l}\text { Severe storm }- \text { Bright, dynamic, colorful aurorae. Aurora } \\
\text { seen around } 50^{\circ} \text { latitude }\end{array}$ \\
\hline 9 & $\begin{array}{l}\text { Intense storm - Aurorae seen around } 40^{\circ} \text { latitude. Red } \\
\text { aurorae and coronae very likely. Most often caused by } \\
\text { powerful coronal mass ejection }\end{array}$ \\
\hline
\end{tabular}

The Kp Index describes the disturbance of Earth's magnetic field caused by the solar wind. The faster the solar wind blows, the greater the turbulence. The index ranges from 0 (low activity) to 9 , which indicates that an intense geomagnetic storm is under way. The information and definition of the Kp index are obtained from the Leirvogur Magnetic Observatory.

\section{CONCLUSION}

The Kp index was calculated from data collected by a network of 13 ground-based magnetometer stations at midlatitude locations from the INTERMAGNET. This index was a geomagnetic index in the $\mathrm{H}$-component field. The K-scale was estimated using the quasi-logarithms algorithm without dimension. The magnitudes of $\mathrm{Kp}$ index could indicate geomagnetic storms under the condition of K-scale $>4$. The three-hourly Kp index has been commonly used because the three-hourly $\mathrm{Kp}$ index was relatively stable for lowvariability geomagnetic activity. The hourly $\mathrm{Kp}$ index represented the level of auroral absorption with a more accurate characterization. For future research, the $\mathrm{Kp}$ index with a high sampling rate (e.g., < $\mathbf{1}$ hour) could be a good issue, so that a very accurate characterization was characterized the more detailed geomagnetic activity of global region.

\section{DATA AVAILABILITY}

Source of the Kp indices: http://wdc.kugi.kyotou.ac.jp/kp/index.html.

\section{ACKNOWLEDGMENTS}

The authors are grateful to the World Data Centre for Geomagnetism, Kyoto; the geomagnetic observatories and Leirvogur Magnetic Observatory.

The author is also grateful the supporting of Prof. Dr Yuan Mei in Taiwan and all of my friends in Taiwan and China

\section{AUTHOR CONTRIBUTIONS}

designed the research; performed the research; analyzed the data; and wrote the paper.

\section{REFERENCES}

[1] J. W. Lin, "Real-time Magnetic Observatory Network: A Review," European Journal of Environment and Earth Sciences, Vol. 2(5), pp. 1-2, 2021. doi: 10.24018/ejgeo.2021.2.5.177.

[2] J. Bartels, N. H. Heck, H. F. Johnston, "The three-hour-range index measuring geomagnetic activity," Journal of Geophysical Research, Vol. 44 (4), pp. 411-454, 1939. doi: 10.1029/TE044i004p00411.

[3] J. Bartels, J. Veldkamp, "International data on magnetic disturbances, fourth quarter," Journal of Geophysical Research, Vol. 59 (2), pp. 297 302, 1954. doi: 10.1029/JZ059i002p00297.

[4] K. Davies, "Ionospheric Radio," The Institution of Engineering and Technology, IET Digital Library, 600 pp, 1990. ISBN: 9780863411861 doi: 10.1049/PBEW031E.

[5] B. G. Hansen, E. Willekens, "The generalized logarithmic series distribution," Statistics \& Probability Letters, Vol. 9 (4), pp. 311-316, 1990. doi: 10.1016/0167-7152(90)90138-W.

[6] M. Menvielle, N. Papitashvili, L. Häkkinen, C. Sucksdorff, "Computer production of $\mathrm{K}$ indices: review and comparison of methods," Geophysical Journal International, Vol. 123 (3), pp. 866-886, 1995. doi: 10.1111/j.1365-246X.1995.tb06895.x.

[7] Y. J. Chen, K. Suzuki, H. Mahara, T. Yamaguchi, "Quasi-logarithmic spacing law in dewetting patterns from the drying meniscus of a polymer solution," Chemical Physics Letters, Vol. 529, pp. 74-78, 2012. doi: 10.1016/j.cplett.2012.01.046.

[8] E. Geerardyn, Y. Rolain, J. Schoukens, "Design of Quasi-Logarithmic Multisine Excitations for Robust Broad Frequency Band Measurements," IEEE Transactions on Instrumentation and Measurement, Vol. 62 (5), pp. 1364-1372, 2013. doi: 10.1109/TIM.2012.2232474.

[9] P. Wintoft, M. Wik, J. Matzka, Y. Shprits, "Forecasting Kp from solar wind data: input parameter study using 3-hour averages and 3-hour range values," Journal of Space Weather and Space Climate, Vol. 7, A29, 2017. doi: $10.1051 / \mathrm{swsc} / 2017027$.

[10] X. Luan, W. Wang, J. Lei, A. Burns, X. Dou, J. Xu, "Geomagnetic and auroral activity driven by corotating interaction regions during the declining phase of Solar Cycle 23," Journal of Geophysical Research: Space Physics, Vol.118 (3), pp. 1255-1269, 2013. doi: 10.1002/jgra.50195.

[11] R. A. D. Fiori, L. Trichtchenko, C. Balch, E. Spanswick, S. Groleau, "Characterizing Auroral-Zone Absorption Based on Global Kp and Regional Geomagnetic Hourly Range Indices," Space Weather, Vol. 18 (12), 2020. e2020SW002572, doi: 10.1029/2020SW002572.

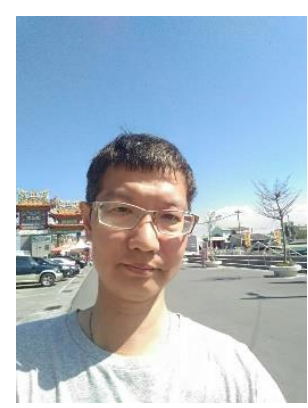

Jyh-Woei Lin received the B.Sc. degree from the Department of Physics, Chung Yuan Christian University, Chung Li City, Taiwan, in 1989, the M.Sc. degree from the Institute of Geophysics, National Central University, Chung Li City, in 1991, the Ph.D. degree from the Institut für Geophysik, ClausthalZellerfeld, Technische Universit ät Clausthal, Germany, in 2000, and the Ph.D. degree from the Department of Electrical Engineering, Southern Taiwan University of Science and Technology, Tainan, Taiwan, in 2019. Since 2019, he is a researcher in the Department of Electrical Engineering, Southern Taiwan University of Science and Technology. Until 2021, he has 71 SCI (SCIE) and EI papers include artificial intelligence, space physics, geophysics, medical sciences, and remote sensing; especially four books publications in Germany and two books in USA. After September 2020, he is also as a Professor in Binjiang College, Nanjing University of Information Science \& Technology, Wuxi, Jiangsu Province, China.

\section{CONFLICTS OF INTEREST}

The author declares that there is no conflict of interest. 